\title{
An Examination of the Causal Relationship Between Tourism and Economic Growth in Ghana from 1987 to 2018
}

\author{
Faustina Erica Fredua $^{1 *} \quad$ Professor Li Yuejun $^{2} \quad$ Shen Hongcheng ${ }^{3}$ \\ 1, 2School of Economics and Management, \\ Zhejiang University of Science and Technology; Hangzhou, CN
}

\begin{abstract}
The growth of every nation is its ability to improve every sector of the economy that provides better outcomes through revenue mobilization and investment. With the Ghana's attention shifted to tourism, it is imperative to identify how tourism could trigger growth in the country. Thus, the study sought to examine the causal relationship between tourism and economic growth of Ghana and its related challenges. The study adopted a mixed method approach in the collection and analysis of data. Both secondary and primary data were used in the analysis of the study. In analyzing the quantitative study, data on tourism and GDP from 1987 to 2018 were used. The study adopted the Johansen Cointegration test and the instrumental variable estimation to identify the causal relationship among the variables. The outcome of the study from the Johansen and Co-integration test instrumental variable showed that there is a unidirectional causal relationship between tourism receipt and GDP growth both in the short run and the long run and a positive significant effect of tourism on economic growth of Ghana. The result showed that government has been the major contributor to the sector. Also, the most challenging issue curtailing the sector was found to be the issue of the COVID 19 pandemic. As such, the study recommended that ensuring publicprivate partnership could improve the sector to ensure growth in the economy. Further extensive research is required to understand the effects of tourism on host communities.
\end{abstract}

Keywords: Tourism, Gross Domestic Product (GDP), Economic Growth, Ghana, Tourism industry, Climate Change.

DOI: $10.7176 / \mathrm{JESD} / 11-20-04$

Publication date:October $31^{\text {st }} 2020$

\section{INTRODUCTION}

The agenda for most countries is to achieve growth through the reduction in the Balance of Payment Deficit, creation of jobs and promoting fiscal discipline. In finding solution to the aforementioned, tourism has gained the root in most African countries, serving as a revenue generation to countries in sub-region (WTTC, 2019). Due to its relevant nature, most governments have come to the realization that this sector does not only increase the foreign exchange earnings, but also serves as an avenue for job creation and stimulation of growth in the economy (Samini, Sadeghi \& Sadeghi 2011). As such, tourism has become an integral sector for most governments in Africa.

\subsection{Problem Statement}

Ghana is endowed with diverse tourist resources. The country is seen to be endowed with natural, cultural and other man-made attractions. The central location of Ghana on the global world as well as the political and economic stability make the country accessible. The rich culture of the country with over 30 festivals celebrated by different ethnic groups at different calendar of the year, with over 30 fortes and castles across the country, handicraft, local cuisines and music, all promote the tourism in the country (Sampson 2016).

Reports from the Ministry of Tourism, Arts and Culture (MOTAC) indicated that the Ghana government has much interest in the sector. As the Ministry was allocated a budget of GHф33,296,543.00 and GHф38,7918,393.00 for 2015 and 2016 financial years respectively. Government's contribution to the sector continued despite the change in government as GHф48,365,959.00 was allocated to the sector in 2018 (MOTAC, 2018). Not only that, both government institutions and non-governmental organization have established various approaches to promote tourism in the country. In 2019, the government of Ghana established a theme dubbed "A Year of Return" as a way to boost the sector for growth. As well, the World Bank approved a $\$ 40$ million dollar facility in support of the Ghana Tourism Development Project in Ghana (World Bank, 2018). This funding is toward a project to enhance the tourism sector's contributions, diversify its impact, and help increase the contribution of the tourism sector to the Ghanaian economy.

Despite the progress and contribution of tourism industry, in Ghana, report from Knoema (2018) clearly reveals that since 2013, the percentage changes of tourism contribution to GDP has remained negative. In 2017, the tourism industry contributed about $5.6 \%$ to the GDP of the country. This tourism contribution to the share of GDP was seen to be around 5.5\% to the economy of Ghana with a percentage of tourism to GDP being $-1.41 \%$. This is not an isolated situation as in the changes between 2016 and 2017 was about $-4.07 \%$. With several interventions provided by the country to tourism, with yet, a percentage change of tourism to GDP remaining negative, there is the need to consider whether the policies in tourism are sustainable to the growth of the sector 
and whether tourism has causal effects on the economy of Ghana should be looked at.

\subsection{Objectives of the Study}

Specifically, the study seeks to examine the long-run causal effects of tourism on economic, investigate the role of government and non-governmental organizations in the tourism industry, identify the challenges faced by the tourism industry and examine the mechanisms adopted to promote the sustainability of the tourism industry in Ghana

\subsection{Hypothesis}

$H_{0}$ : There is no causal effect of tourism on the economic growth of Ghana

$H_{a}$ : There is a causal effect of tourism on the economic growth of Ghana

\subsection{Justification}

Tourism being the fourth highest contributor of foreign earnings to Ghana shows its relevant nature to the economy (Sampson 2016). However, there are some challenges that pose threats to the growth of the sector. Understanding the problems of the sector is the best step to be taken in improving the sector. The need for this study cannot be overlooked because most studies conducted in this sector only focused on tourism planning (Teye, 2007; Ghosh \& Kotey 1973; Ayittey 1975). This study on the other hand focuses on the impact of tourism to the economy of Ghana as well as addressing challenges faced by the sector and ways of sustaining the growth of the sector.

\subsection{Literature Review}

The chapter is mainly concerned with the theoretical review on how tourism impacts on economic growth.

\subsection{Empirical Literature}

The 2018 World Travel and Tourism Council annual report revealed that tourism in Africa is growing at 5.3\% as compared to the global average growth of $3.9 \%$ and contributing to the broader African GDP growth rate of $3.2 \%$. The report also indicated that about 24.3 million jobs have been created as a result of Tourism and the sector has contributed to about $6.7 \%$ of total employment with an estimated $\$ 194.2$ billion contribution to the African region making up of $8.5 \%$ to GDP. Thus, tourism accounts for about $3 \%$ to $10 \%$ of GDP growth in the continent. In an approach of the government of Ghana to increase its foreign earnings for example, the year of 2019 was regarded as a year for attracting international tourists to Ghana in an initiative dubbed "The year of return". This is not an isolated case, as the tourist sector in Egypt contributed about 11.9\% to its GDP (WTTC, 2019). Tourism is said to also contribute about $61.0 \%$ to the country's total export. The statistics clearly show that in general, tourism has become one of the major contributors to GDP growth in most economies in Africa and around Globe.

From the foregoing, several studies have delved into the causal and long-run effect of tourism and economic growth in Western countries. However, relatively speaking, fewer studies have been looked at when considering the causal relationship between tourism and economic growth in Africa. With most government in the continent striving to increase its economic growth and improve the other macroeconomic indicators, then there is need to look at the causal relationship between tourism and economic growth in Africa.

The role of tourism in local economic development in Ghana has been acknowledged by Arthur \& Mensah (2007) for example. In their study which highlighted the Elmina Cultural Heritage and Management Programme (ECHMP) in Ghana, Arthur \& Mensah (2007) identified stakeholder participation, involvement of the private sector, effective management of urbanization and a collaboration between the government organizations and the private investors as critical points of consideration for a successful tourism project.

The success of any tourism venture however hinges on whether the setting in which such investments are made are supportive of such ventures. In understanding determinants of community acceptance and support of tourism projects or development in Ghana, Sirakaya, Teye \& Sönmez (2002) identified from their study in the Central region of Ghana that various socio-psychological variables such as what people think of tourists and how tourism affects them, employment status of the individual, being a member of community organisations and knowledge of tourism development projects in the communities go a long way to determine support for the industry and investments in it. Against every argument for the role of tourism in development, acceptance of tourism and hospitality industry by residents. Pro-poor tourism seeks to improve tourism without neglecting the poor residents of the destinations. There is evidence of activities within the tourism industry in Ghana that lack elements of ecofriendliness even though some patchy efforts are beginning to emerge in the sector to that regard. The work of Mensah (2007) for example identified that management of hotels even in the capital city of the country did not engage in eco-friendly activities such as using solar energy or recycling even though some of the hotels of multinational standards do so. The only activities engaged in by these hotels worth describing as eco-conscious activities are ones targeted at environmental management activities which seek to achieve clean, green and healthy environments and using energy efficient bulbs, re-using linen and towels (Ibid). The study however failed to give 
insight to the factors accounting for the inactivity or activity of hotels towards hospitality that captures environmental sustainability.

\subsection{Theoretical Review of Economic Tourism and Economic Growth: The Solo Growth Model}

Different kinds of capital, such as physical capital, human capital, resources, environment, and infrastructures, play varying role in economic growth and development. As these capitals vary over time due to depreciation, consuming and accumulation by people's efforts, it is significant to study how these capitals and their exchange values influence economic growth over time. One of the early theories of growth during the early 1900s was the Solow Growth model and the model takes into account most factors of production in economic growth of a particular nation within a time frame. According to the model, economic is a function of labour force, productivity and capital formation. It considers the long-run economic growth as a function of capital accumulation (land and resources, infrastructure, etc), labour and productivity.

Among various factors of production, the one that is of interest to the study is the capital accumulation factor. The model assumes that there is a relationship between land, infrastructure etc. and economic growth. Since this study considers how tourism influences economic growth in Ghana, then these factors are of importance to the study. In essence, the Solow model suggests that for an economy to achieve higher GDP growth, there must be the availability of resources in terms of infrastructure, natural resources, and other capital to aid in this process. Thus, when resources within the society are used efficiently, economic growth is likely to be achieved. In relation to tourism, the theory suggests that when a country's natural resources, infrastructure and man-made resources are used efficiently, they could aid in balance of payment surplus, thereby improving GDP of the country, thus, economic growth in the long run (Fayissa, Nsiah \& Tadasse 2008; Ardahaey, 2011). As such, from the perspective of Solow model, there is a causal relationship between tourism and economic growth.

\subsection{RESEARCH METHOD}

This chapter of the study focuses on the methods and approaches adopted to conduct the study. It looks at the research design, sources of data, method of data collection, the sampling technique and the analysis of data to meet the objective of the study

\subsection{Research Design}

The study is conducted with the aid of both quantitative and qualitative method. Thus, mixed method approach was the type of study adopted. The used of both qualitative and quantitative approach allowed the study to adopt descriptive research design. This design allows the researcher to conduct the study using a mixed method approach (Greenwood \& Levin 2006).

\subsection{Sources of Data}

The sources of data will involve both primary and secondary data. The primary data were collected from various tourism centers in Ghana. The secondary data for the analysis spanned from 1987 to 2018 and were obtained from World Bank, IMF, UNDP and WDI. The secondary data to form part of the study include Tourism revenue receipt, Gross fixed capital formation, Population, Trade openness, Taxation and Inflation will form the explanatory variable for the study.

\subsection{Estimation/Econometric methods Using Secondary Data}

\subsubsection{Model Specification}

The model for the study depicts the dependent variable and independent variables of the study. GDP is termed as the dependent variable in the study. Thus, tourism, Gross Fixed Capital Formation, Population, Trade Openness, and Taxation, will form the controlled variables.

$L G D P=\beta_{1}+\beta_{2} L T R M_{t}+\beta_{3} L P O P_{t}+B_{4} L O P E N_{t}+\beta_{7} L I N F_{t}+\beta_{10} L G D P_{t-1}+e_{t}$

LGPD represents the log Gross Domestic product, LTRM is the log of tourism revenue receipt. Also, LPOP represents population, LOPEN expresses Trade openness, and LINF represents inflation. The study will also employ the lag of GDP and the error correction term e. $\beta$ represented the parameter for the study

\subsubsection{Stationarity}

The approach that will be adopted in this study is that of Augmented Dicky Fuller test, which the unit root test is. The use of this approach is to test for the unit root for the joint null hypothesis to find out if it was non-stationary as the data used was based on time series.

3.3.3 Cointegration

This test is carried out to know the order of integration of the variables under study. This allows us to know whether there is a co movement between the dependent variable and the respective individual variables, especially in a long run. There is cointegration between variable if they have the same order of integration and possess a stationary error term. This study tests for cointegration using the Augmented Dickey Fuller test and Johansen cointegration 
test.

The long-run and short-run relationships investigated was estimated using Augmented Dickey Fuller and Johansen cointegration test because of its ability to make use common component for the interpretation of result (Johansen 1991). The Augmented Dickey Fuller Approach and Johansen Test were used to check if there is stationarity and co-integration among the estimated variable. The error correction model was used to check for previous disequilibrium and subsequently factor them (if any) into the estimation. Therefore, spurious results are avoided. The test examines the null hypothesis of no levels relationship between the series in against the alternative hypothesis of the presence of such relationship. The null hypothesis of no co-integration $\left(H_{0}: \pi_{1}=\pi_{n}=0\right)$ is tested against the alternative hypothesis of the presence of co-integration relationship $\left(H_{1}: \pi_{0} \neq \pi_{1} \neq 0\right)$.

Using the Johansen Cointegration Test; the study can conclude of cointegration if the computed static statistic and the max eigen statistic are greater than the upper bound critical value. Alternatively, if the computed static statistic and the max eigen statistic are lower than the lower band value, there is no co-integration. A statistic in between the lower and upper band value depicts inconclusive results.

The specified Augmented Dickey Fuller Test model and Johansen cointegration test is stated below;

The specified Augmented Dickey Fuller Test model and Johansen cointegration test is stated below;

$$
\begin{aligned}
& L G D P=\beta_{1}+\beta_{2} L T R M_{t}+\beta_{3} L P O P_{t}+B_{4} L O P E N_{t}+\beta_{5} L I N F_{t}+\beta_{6} L G D P_{\mathrm{r}-1}+\theta_{t}
\end{aligned}
$$

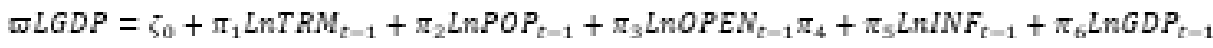

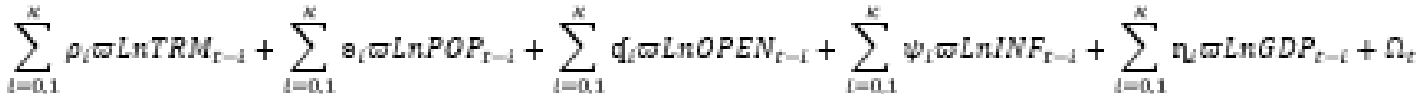

\subsubsection{Instrumental Variable (IV) Estimation}

The study recognizes the likelihood of endogeniety as such, an estimation that considers such effect and also takes care of the error term in its estimation. In effect, the instrumental variable propounded by Caner and Hansen (2004) was adopted in this study to eliminate endogeneity issues and to aid in the establishment of the actual effect of tourism on economic growth of Ghana. Climate change was selected as the instrumental variable in the estimation as it is a naturally born variable that and prevents error term as used in the work of Oduniyi and Tekana (2019). The study further used the Generalised Method of Moment for robust and eliminate heteroskedasticity.

\subsection{Method Data of Collection}

This primary data collected for the study was mainly for the qualitative part of the study. Primary data is data collected during a study obtained through direct contacts from respondents through the use of interview. A good part of making use of primary data is that it represents the specific reason for the intended research $(\mathrm{Gray}, 2019)$

\subsection{Data Analysis}

The study was analysed using thematic approach and inferential approach. The thematic approach was conducted from the primary data gathered and the responses given by participants were coded into themes before they well analysed (Cohen 2013). For the inferential analysis, the study solely focused on the secondary data used for the quantitative analysis. It adopted the cointegration autoregressive Distributed lag approach and instrumental variable estimation for analysis of the study.

\subsection{Validity, reliability and trustworthiness of the data}

Diagnostic tests were utilized for checking the validity of the fitted model. In this study, VECM based diagnostic tests are reported to check the validity of the fitted model. A Lagrange-multiplier test was used to investigate a possible serial correlation in the error term. CUSUM and CUSUMSQ will also use to check or test the stability of the estimated parameters in the model. In addition, post estimation method of endogeneity was also conducted to test for the validity of instrumental variable regression. In relation to the qualitative part of the study, face validity was used for and was achieved through thorough literature reviewed and developed using theoretical definitions and validated measurement instruments from previous studies (Gray 2019).

\subsection{DISCUSSION AND FINDINGS}

The study simply looks as the unit root of the variables used, it also tests for co-integration, instrumental variable, VECM and VER test.

\subsection{Unit Root Test Results}

The study carried out a unit root test on both the independent and dependent variables. The Augmented Dickey 
Fuller Test was used as to check for the stationarity of variables and also to check for the order of integration. This was done to ensure that there is no integration among the order greater than one.

TABLE 4. 1 AUGMENTED DICKEY FULLER TEST

\begin{tabular}{lllll}
\hline Variables & \multicolumn{2}{c}{ Level } & \multicolumn{2}{c}{ First Difference } \\
\cline { 2 - 5 } & Intercept & Trend & Intercept & Trend \\
LNOPEN & -2.405721 & -2.136073 & $-3.544529^{* *}$ & $-3.823050^{* *}$ \\
LNPOP & -1.673868 & -1.673868 & $-3.824412^{* * *}$ & $-3.534082^{* *}$ \\
LNTTRADE & -1.437135 & -1.694367 & $-5.103023^{* * *}$ & $-5.510649^{* * *}$ \\
LNINF & -2.134151 & -1.993552 & $-3.396795^{* *}$ & $-3.558917^{* *}$ \\
LNRGDP & 3.108933 & -2.614024 & $-3.398056^{* *}$ & $-3.521715^{* *}$
\end{tabular}

$\approx *$ denotes statistically significant at the $\mathbf{5}$ percent and ${ }^{\star \star \star *}$ denotes statistically significant at thel percent

Source: Computation obtained on World Development Indicators

From the result of table 4.1, it is evident from the Augmented Dickey fuller test that that tourism is nonstationary both either with or without trend in level. The study therefore indicates that at level, tourism is nonstationary. In this instance, the study therefore had to go further and perform the first difference to check for the stationarity. Trade is observed to be integrated at order one, I (1). It is also observed that the controlled variables, population, trade, and inflation, are also non-station in level at the intercept and trend. However, population, trade and tourism tend to be stationary at the first difference. The dependent variable, GDP, also becomes stationary only at the first difference. Given that the variables to be estimated are stationary at order one, I (1), it is appropriate to use Johansen co-integration test for the estimation of variables.

\subsection{Johansen's Co-integration Test for Common Components}

This section of the study estimates cointegration test among the variables that are under study. It uses the trace statistic and the max statistic to indicate the cointegration.

Table 4. 2 Johansen's Co-integration Test for Common Components

\begin{tabular}{lllll}
\hline $\mathrm{H}_{0}$ & Trace Statistic & Critical Value & Max-Eigen Value & Critical Value \\
\hline None & 98.10775 & 69.81889 & 38.95285 & 33.87687 \\
At most 1 & 59.15491 & 47.85613 & 34.41935 & 27.58434 \\
At most 2 & 24.73555 & 29.79707 & 20.05557 & 21.13162 \\
At most 3 & 4.679981 & 15.49471 & 4.609775 & 14.26460 \\
At most 4 & 0.070207 & 3.841466 & 0.070207 & 3.841466
\end{tabular}

88 denotes statistically significant at the 5 percent and ${ }^{* * *}$ denotes statistically significant at the1 percent Source: Computation obtained on World Development Indicators

In order to perform the Johansen test, variables were used in their log transformation of the raw variables to meet the requirement for performing Johansen cointegration test. The testing of cointegration generated two results. That is the trace and the max statistics. It supposes that if the values from the trace and max statistics are greater than the $5 \%$ of the critical value, we reject the null hypothesis that there is no cointegration equation among the variables.

From table 4.2, the trace statistic value is greater than the critical value with null hypothesis that there is no cointegration at $5 \%$ level of significant. In addition, trace statistic value on rank 1 is greater the critical value at $5 \%$ level of significant. This shows that there is cointegration equation from the estimation of trace statistic. The result was not differnet from the outcome of Max-Eigen statistic. In essence, both the trace statistic and the Max-Eigen statistic show that there is cointegration equation. This implies that there is a long relationship among tourism, inflation, population growth, trade and GDP. To this effect, the study proceeded to test for the direction of causality in the short run and the long run among the variables VECM.

\subsection{Causality Test of Tourism, Population, Inflation Trade and GDP}

Causality test was conducted under this section to identify the causal relationship and the direction of the relationship among the variables. It considers the causality among tourism, population growth, inflation, trade and 
GDP under table 4.3.

The outcome of the study tends to depict the notion that there is bi-directional causality between international trade and population growth. Thus, international trade and population growth in Ghana has causality effect on each other at $5 \%$ level of significant $\left(6.15^{* *}\right.$ and $\left.9.10^{* *}\right)$. The result also indicates that in the short run, there is unidirectional causality effect between tourism and international trade in Ghana. Implying that tourism has effect on international trade, however, international trade has no short run effect on tourism at $5 \%$ level of significant $\left(7.05^{* *}\right)$. Likewise, GPD growth was also observed to have uni-directional causality effect on international trade. In relation to the causal effect of tourism receipt in Ghana and GDP growth, the result of the study depicts unidirectional causal effect. Thus, receipt on tourism was observed to have causal effect on GDP growth in the short run at $1 \%$ level of significant $\left(11.07^{* * *}\right)$. It therefor implies that in the short run, activities regarding tourism in terms of receipts propel the economic growth of Ghana.

In the long run, at 5\% level of significant, inflation, population growth, and international trade have long run granger cause on GPD growth of Ghana. The result indicated that in the long run, there is a bi-directional causal effect between GDP and international trade, however, unidirectional cause between GDP, population growth and inflation. The result from the estimation also implies that in the long run, tourism receipt in Ghana has unidirectional causal effect on the economic growth of the country.

\subsection{Causal estimation with Instrumental Variable Regression}

In order to establish a clear and conceivable causal reference between GDP and tourism, there was the need to conduct regression estimation with the aid of instrumental variable. Climate change was selected as the instrumental variable.

Table 4. 4 Generalized Method of Moment (GMM) in Instrumental Variables Estimation of GDP Growth

Model (GDP)

\begin{tabular}{llll}
\hline Variables & Coefficient & Robust Std. Err & Prob (z) \\
\hline LNTOUR & .9080027 & .1936928 & 0.000 \\
LNPOP & -.1024441 & .170279 & 0.547 \\
LNOPEN & 0.084375 & 0.0398946 & 0.043 \\
LNINF & -.0099569 & .0274203 & 0.717 \\
\hline R-squared & 0.8683 & & \\
Observations & 32 & & \\
\hline
\end{tabular}

Source: Author 2020; Computation based on information from World Bank, IMF and HDI.

The outcome of the study indicates that both the population growth of Ghana and the inflationary rate in the country do not have significant effect on the growth of the nation. However, the outcome indicated a negative relation between the economic growths of the country. The result of the GMM estimation in instrumental variable indicates that at $5 \%$ level of significance, international trade has positive effect on the economic growth of the country. In effect, an increase in international trade of Ghana result in the growth of the economy.

In relation to tourism which is the main explanatory variable, the result revealed that at $1 \%$ level of significant, tourism of Ghana has positive significant effect on the economic growth of the country. Thus, when tourism receipt of the country increases, it result in a positive growth of the economic and fall in tourism receipt also results in the fall of the economic growth of the nation. This outcome of the study showed that tourism and international trade have significance effect on the economic growth of Ghana at $1 \%$ and $5 \%$ level of significant respectfully.

4.5 Qualitative Insight to Nature of Tourism Business in Ghana and Role of the Sector in Economic Growth Beyond the secondary data, the study sought to explore the situation through qualitative interviews. The interviews showed that largely, tourism business in Ghana is characterized by hotels, antique sites and natural site seeing. The most profitable of these however are the hotel businesses.

"The parks and other natural scenes are occasionally visited. During festivities and vacations, you would see people going to those places but most of them are dormant. I am not sure they can compare their successes to us who operate hotels. It is an all-year-round operation for us" [Yakohene].

Local tourism industries pay taxes even though some of them hold that because their earnings tend to be low sometimes, they are unable to meet their tax obligations. Also, hotels engage in other growth and expansion activities such as building new hotels in other sites, expanding existing ones and operating bigger restaurants that supply food to people other than those who patronize hotel and other events.

The manager of one of the antique sites in Accra that was interviewed for example said, "even though we are a public organisation, we contribute our due in terms of tax. Of course, I would admit that we are not able to pay always. The tax people understand our difficulties. This year started as one of our best years with the 'Year of 
Return thing'. You know the coronavirus has turned everything upside down." [Kojo]

For the hotels however, the Ghana Tourism Board and Ghana revenue authorities were found to operate in concert to ensure compliance when it comes to revenue oversight and tax compliance. The hotels because of the close supervision hardly evade tax and thus are regular tax payers.

It can be said based on these interview excerpts that local tourism industries contribute their due when it comes to development through employment, tax obligations, and foreign exchange earnings and other analogous operations and businesses.

\subsection{Role of Government and Non-governmental Organisations in the sector in Ghana}

The interviews showed that, to private businesses, government is largely seen as the regulator and tax collector. Some however noticed the role of government in terms of the provision of needed infrastructure for the development of the sector. Aside publicly owned centers or tourism facilities, there is no direct investment from government in the sector. Even though there are programs and policies from government aimed at developing the sector, there seems to be a cold air of dissatisfaction among industry players on government commitment to the development of the sector. Non-governmental organisations are generally seen as regular clients because of their ties with expatriates who visit the country for their intervention activities.

The need for growth in the tourism sector is a collaborative effort. In this regard the study found whether there has been some support provided by successive government to promote the growth of the industry. Participants sampled for the study provided varying responses.

The result of the study indicated that there has been some financial support by the government of Ghana as a stimulus package to promote the growth of the industry. It was discovered that this package is as result of the Novel Corona Virus that has impacted negatively on the sector. Thus, the government in its attempt to ensure its sustainability. In addition, responses from participants concluded that 2019, which the Ministry of Tourism Art and Culture launched "The year of Return" has also contributed to the sustainability of the industry is it is what has actually held most organization during this difficult period.

The pliability of the roads leading to tourism facilities especially the wildlife and forest reserves is a daunting problem to the sector. Because people cannot move with ease to most of these facilities which are generally located at the remote areas of the country, patronage is quite on the low side. The government is largely blamed for not targeting development of roads leading to tourist sites.

\subsection{Challenges faced by the Sector and Mechanisms for Sustainable Tourism in Ghana}

This section of the study examined the challenges faced by the tourism sector and mechanisms adopted for ensuring sustainability of the industry have been explored. To this regard, the study found that the notable challenge to the tourism industry currently in Ghana is the outbreak of the novel coronavirus (COVID 19). Also, poor national economic and fiscal development challenges which translates into poor local patronage, lack of local government support, lack of the needed skills to work in the industry coupled with unstable national leadership for the sector. Other challenges range from infrastructure base needed to support transportation and communication needed to make destinations attractive and pliable for prospective tourists and occasional conflicts with host communities. One thing noted by some of the study participants is the poor economic situations of the country which account for low local patronage. most of the people who use tourism facilities in some countries are youths. Here in Ghana, most of our youth are unemployed and so they cannot afford leisure and pleasure offered by those in tourism industry". "To be honest, even though our services are very cheaper than what is on the international community, the average Ghanaian sees tourism as expensive and a reserve for the rich of our society. On the Mechanisms aimed at promoting a sustainable tourism industry in Ghana, it was identified that even though knowledge exists on sustainable practices and mechanisms, enforcement remains the gap between knowledge and practice. The National Tourism Development Plan (2013-2027) aims at improving the database on tourism industry in Ghana, rewarding customer loyalty, engaging host community knowledge for improving local tourism, local authorities need to have people who oversee tourism in their decentralized jurisdictions and protection of reserves from damage through regulated patronage of such areas. "We are required to be environmentally friendly in our operations. The Ghana tourism board can seize your certificate if you fail to be a responsible business. Aside the fact that the National Tourism Development Plan aims at collating data on the tourism organisations in the country, some of the industry players in addition believe that "...collaboration is the way forward. We need to have a network. We cannot only be in competition, we must partner.

\subsection{Discussion of Findings}

Tourism is recognized as one the key areas of the economy that promote growth (Xin, Tribe and Chambers 2013). Different scholars have differing notion about the impact of tourism to the economic growth of a country. The outcome of the study indicated that there is a relationship between the explanatory variables, tourism, and the dependent variable GDP. It suggested that tourism cointegrate with GDP. The result of the study was consistent 
with the report of Dritsakis (2004), as it indicated that there is cointegration among tourism, real effective exchange rate and GDP. Similarly, the work of Pan and Dossou (2019) is consistent with the outcome of the study that there is cointegration between tourism and GDP.

The study tested for the causality effect and the outcome of the study showed indeed, there is both short and long run causality effect. The result revealed that tourism receipt in Ghana has unidirectional causal effect on GDP in the short run and the long run. It is no surprising that the outcome of this study confirms the work of Dritsakis (2004) on the notion that there is a causal relationship between international tourism earnings and economic growth of the country. Likewise, outcome of the study meets the findings of Akinboade and Braimoh (2009), which revealed that tourism is one of the major indicators of economic growth in South Africa as their result showed a unidirectional cause of tourism and GDP in both short run and long run.

Using the instrumental variable estimation, the result clearly indicated that there is a positive relationship between tourism of the country and the economic growth of the nation. The result is not in isolation as that work of Areski et al., (2009) which looked at the effect of tourism on economic growth, also adopted instrumental variable for the estimation. The result of their study also showed that specialization in tourism positively influence the growth of the economy. In essence, the estimator for the work of Areski et al., (2009) validates that of the one used in this study. Likewise, a report from Adamou and Clerides (2009) which focused on the relationship between tourism, specialization and GDP growth, concluded from instrumental variable estimation that growth in the tourism industry result in economic growth whereas less growth in the tourism industry leads low economic growth in the country.

Po and Huang (2008), in their study which used cross sectional data of 88 countries however, failed to consider the issue of endogeneity problem. Their study concentrated on identifying how tourism specialization could improve economic growth. Even though they outcome of the study showed a positive significant effect of tourism specialization on economic growth just as the outcome of this study, the result may have been influence by the presence of endogeneity as such issue was not factored into account when estimating the result. Government is largely perceived among private tourism business owners as only a regulator through the Ghana Tourism Board and the Trade Ministry and a collector of taxes. Government investment in the sector remains quite low even though there are some publicly owned antique sites in the country. The findings of this current study are largely in agreement with the earlier work of Alhassan (2017:10) who identified that the role of the government in the tourism include "public protection, social tourism, stimulation, entrepreneurship, legislation and regulation, planning, and coordination". It is good for the sector as well to learn from Ruhanen (2013) who intimated that the motive for the intervention of the government in the sector needs to transcend economic reasons to addressing issues pertaining to the unwillingness from locals to agree and back tourism development, and the negative impacts of tourism on local population have extended government's role to add environmental and social concerns.

\subsection{RECOMMENDATION AND CONCLUSION}

Tourism has been a key contributor the growth of many economy. With limited literature of tourism on the economy of Ghana, there was the need to delve into the causal effect of tourism on the economy of Ghana. the study adopted the Johansen Co-integration test to test for the long run and the short effect of tourism on the economy of Ghana. The outcome of the study suggests that there is a unidirectional causal effect of tourism on GDP growth either in the long run or the short run. Thus, there is a short run effect of tourism on the economy of Ghana and there is a long run causal effect of tourism on the economic growth of Ghana. In addition, instrumental variable estimation showed that tourism had positive effect on the economic growth of Ghana. This suggests that for Ghana to achieve economic growth, there should be improvement in the tourism to propel growth in the economy as the tourism significantly cause GDP growth both in the short run and the long. Poor performance within the industry however limits tax compliance which is expected to have effects on extent to which the sector positively influences economic growth.

The study therefore recommends that the role of government needs to be deepened and more informed publicprivate partnerships are required for sector growth. The challenges of the sector require government investment in infrastructure to improve accessibility of sites and creating the needed legal and economic atmosphere to empower local governance involvement and create the economic capital needed to improve local tourism patronage. The absence of a clearly defined plan for ensuring sustainable is a threat to the future prospects of the sector.

Policies must be enacted on the environment, there is the need for government to consider the issue of climate change in its policy formulation as that could have indirect effect on the growth of the economy at large. There is the need for industry players to take advantage of the diversities of cuisine across the numerous cultures of the country to create a Ghanaian niche of foods to attract more tourists. Further extensive research is required to understand issues of effects of tourism on host communities and mechanisms for ensuring sustainable tourism industry growth as a means of reducing unemployment in Ghana. 


\section{References}

Adamou, A., \& Clerides, S. (2009). Prospects and limits of tourism-led growth: The international evidence. The Rimini Centre for Economic Analysis WP, 41-09.

Akinboade, O. A., \& Braimoh, L. A. (2010). International tourism and economic development in South Africa: A Granger causality test. International Journal of Tourism Research, 12(2), 149-163.

Akyeampong, O. A. (2011). Pro-poor tourism: residents' expectations, experiences and perceptions in the Kakum National Park Area of Ghana. Journal of Sustainable Tourism, 19(2), 197-213.

Ardahaey, F. T. (2011). Economic impacts of tourism industry. International Journal of Business and Management, 6(8), 206-215.

Areski, R., Cherif, R. and Piotrowski, J. (2009), "Tourism specialization and economic development: evidence from the UNESCO World Heritage list", IMF No. 176, pp. 1-24, available at www.imf.org/external/pubs/ft/wp/2009/wp09176.pdf

Arthur, S., N. A. \& Mensah, J. V. (2006). Urban management and heritage tourism for sustainable development: The case of Elmina Cultural Heritage and Management Programme in Ghana. Management of Environmental Quality: An International Journal, 17(3), 299-312.

Ayittey, G. (1975). The Tourism Multiplier Expenditure in Ghana. Accra: Department of Economics, University of Ghana/Ghana Tourist Control Board

Bezmen, T. (2006). Estimating the impact of tourism on economic development in Latin America. Academy of Economics and Finance, Houston, TX, February.

Cohen, L., Manion, L., \& Morrison, K. (2013). Action research. In Research methods in education (pp. 368-385). Routledge.

Dritsakis, N. (2004). Tourism as a long-run economic growth factor: an empirical investigation for Greece using causality analysis. Tourism economics, 10(3), 305-316.

Etikan, I., Musa, S. A., \& Alkassim, R. S. (2016). Comparison of convenience sampling and purposive sampling. American journal of theoretical and applied statistics, 5(1), 1-4.

Fayissa, B., Nsiah, C., \& Tadasse, B. (2008). Impact of tourism on economic growth and development in Africa. Tourism Economics, 14(4), 807-818.

Ghosh, R. and Kotey, R. (1973). Tourism and Foreign Exchange Earnings in Ghana. Accra: Institute of Statistical, Social and Economic Research, University of Ghana.

Gray, D. E. (2019). Doing research in the business world. Sage Publications Limited.

Greenwood, D. J., \& Levin, M. (2006). Introduction to action research: Social research for social change. SAGE publications.

Gwenhure, Y., \& Odhiambo, N. M. (2017). Tourism and economic growth: A review of international literature. Turizam: međunarodni znanstveno-stručni časopis, 65(1), 33-44.

Knoema (2018). Ghana - Contribution of travel and tourism to GDP as a share of GDP. Retrieved from: https://knoema.com/atlas/Ghana/topics/Tourism/Travel-and-Tourism-Total-Contribution-toGDP/Contribution-of-travel-and-tourism-to-GDP-percent-of-GDP accessed on 1 November 2019

Mensah, I. (2007). Environmental management and sustainable tourism development: The case of hotels in Greater Accra Region (GAR) of Ghana. Journal of Retail \& Leisure Property, 6(1), 15-22.

Ministry of Tourism, Arts and Culture (MOTAC) (2017). Medium term expenditure framework for 2017-2019.

Ministry of Tourism. (2013). National Tourism Development Plan (2013-2027). Accra. Retrieved from https://www.ghana.travel/wp-content/uploads/2016/11/Ghana-Tourism-Development-Plan.pdf

Pan, X. M., \& Dossou, T. A. M. (2019). The relationship between tourism and sustainable economic growth in the Republic of Benin. Current Issues in Tourism, 1-10.

Ruhanen, L. (2013). Local government: Facilitator or inhibitor of sustainable tourism development? Journal of Sustainable Tourism, 21(1), 80-98.

Sak, N., \& Karymshakov, K. (2012). Relationship between tourism and economic growth: A panel Granger causality approach. Asian economic and financial review, 2(5), 591.

Sampson E., (2016). Ghana's Tourism Potential. Retried from: http://www2.statsghana.gov.gh/docfiles/publications/Tourism\%20Market\%20Trends\%20Report\%20in\%20 Ghana.pdf Accessed on 1 November 2019

Sinclair, M. T., Blake, A. D. A. M., \& Sugiyarto, G. U. N. T. U. R. (2003). The economics of tourism. Classic reviews in tourism, 22, 54.

Sirakaya, E., Teye, V., \& Sönmez, S. (2002). Understanding residents' support for tourism development in the central region of Ghana. Journal of travel research, 41(1), 57-67.

Sirakaya, E., Teye, V., \& Sönmez, S. (2002). Understanding residents' support for tourism development in the central region of Ghana. Journal of travel research, 41(1), 57-67. 